\title{
"A ESCOLA PEDIU A DOCUMENTAÇÃO E EU TIVE QUE EXPLICAR QUE SÓ TEM O PROTOCOLO DA POLÍCIA FEDERAL": CRIANÇA REFUGIADA E EDUCAÇÃO
}

\author{
Maria Fernanda Rezende Nunes \\ DOMENIQUE SENDRA HEIDERIQUE \\ Universidade Federal do Estado do Rio de Janeiro (UNIRIO), Rio de Janeiro, Brasil
}

\begin{abstract}
Resumo: Considerando o conceito da dupla vulnerabilidade da criança refugiada, este artigo se propõe a iluminar as condições com as quais essas crianças se inserem nos estabelecimentos de ensino, a partir do olhar de suas mães. Para tanto, o trabalho busca relacionar entrevistas realizadas com cinco mulheres refugiadas, nacionais da República Democrática do Congo, que possuíam filhos matriculados na rede pública no ano de 2019, com os aparatos legais que regulamentam a educação no Brasil, especificamente no que tange à documentação para acesso à instituição educacional. A análise realizada permite reconhecer três condicionantes que trazem à luz os desafios da integração de crianças refugiadas: as dificuldades de acesso à escola pública devido ao desconhecimento da validade do documento de refúgio, a língua como barreira para a integração e o preconceito vivido dentro do ambiente escolar.
\end{abstract}

Palavras-chave: Educação. Refúgio. Infância. Escola Pública.

O mundo esquece tanto que nem sequer dá pela falta do que esqueceu. (José Saramago, O Ano da Morte de Ricardo Reis)

\section{INTRODUÇÃO}

Nos últimos anos o mundo tem visto crescer o número de pessoas que saem de seus países de origem em busca de refúgio e proteção. No meio acadêmico as produções sobre o tema circundam, principalmente as questões de direito ou relações internacionais, com análises e discussões aprofundadas sobre crises migratórias, aplicabilidade das convenções que discorrem sobre definições de refúgio, entre outras. Todavia, no campo da educação, são escassos os estudos que relacionam o refúgio com a inserção das crianças na escola e seus possíveis obstáculos. Tendo como pressuposto que tais assuntos possuem real importância, uma vez que o Brasil se torna país de acolhimento de refugiados, este artigo se propõe a iluminar em quais condições crianças em situação de refúgio se inserem nos estabelecimentos de ensino a partir do olhar de suas mães. Para tanto, o trabalho busca relacionar entrevistas realizadas com cinco mulheres refugiadas, nacionais da República Democrática do Congo, que possuíam filhos matriculados na rede pública no ano de 2019 com os aparatos legais que 
regulamentam a educação no Brasil, especificamente no que tange à documentação para acesso à instituição educacional, à língua como barreira para a integração e ao preconceito vivido dentro do ambiente escolar.

A observação de refugiados quando estes buscavam atendimento na Organização Não Governamental (ONG) Cáritas Arquidiocesana do Rio de Janeiro, por meio do Programa de Atendimento a Refugiados e Solicitantes de Refúgio (PARES), entre os anos de 2015 e 2019, foi o mote para o desenvolvimento da pesquisa sobre políticas públicas de educação e migração. Reconhecendo que as experiências do refúgio podem variar de cidade para cidade, assim como o acesso à escola pelas crianças, como chave analítica buscou-se abordar o tema tal como recomenda Amorim (2001, p. 11) ao tratar da teoria dialógica de Mikhail Bakhtin: "há sempre uma espessura e uma instabilidade que se devem levar em conta e que remetem à própria espessura e instabilidade do objeto e do saber que estão se tecendo no texto". Assim, partiu-se da premissa que os sujeitos da pesquisa continuam em movimento, como estilhaços e fragmentos, e que a cada vez que deles se fala, novas imagens vão sendo produzidas, numa sucessão de acontecimentos e ações, de acordo com cada época e lugar.

$\mathrm{O}$ artigo está estruturado em quatro itens. $O$ primeiro apresenta o conceito da dupla vulnerabilidade da criança refugiada comparando-as às crianças brasileiras, no sentido de entender a vulnerabilidade da criança refugiada frente às lutas pela educação; o segundo trata da documentação e a busca por reconhecimento; o terceiro aborda a língua e o desafio da alfabetização e o quarto as questões relativas ao preconceito. Ao final se tece considerações.

“NEM A CRIANÇA SABE QUE LÁ TEM GUERRA, A GENTE SAI CORRENDO, PEGA A CRIANÇA PARA NÃO ESCUTAR O QUE ACONTECE, FUGINDO E VINDO PARA CÁ" - A DUPLA VULNERABILIDADE DA CRIANÇA REFUGIADA

O Brasil é signatário de diversos instrumentos internacionais que discorrem sobre a definição de refúgio, os direitos e as estratégias para acolher e proteger as crianças em situação de refúgio no país. Porém, mesmo sendo signatário, não há, até o momento, uma lei que trate especificamente dos cuidados e das prioridades humanitárias para atendê-las.

Thomé (2018, p. 184) relaciona que "a população refugiada, assim como a brasileira, também enfrenta dificuldades quanto à precariedade dos serviços públicos. Mas o grau de dificuldade não é o mesmo para ambas, pois existem outras barreiras aos imigrantes". Dentre as barreiras citadas pela autora está o idioma, a ausência de documentação, a dificuldade de colocação profissional, uma rede de apoio precarizada, o desconhecimento de seus direitos, além da xenofobia e do racismo estrutural.

Entre os abismos existentes entre brasileiros e imigrantes estão o direito ao voto e, consequentemente, a manifestação política como consta no Artigo $14^{\circ}$, inciso $2^{\circ}$ da Constituição Federal de 1988 (CF/88). Dessa forma, "mesmo sendo diretamente afetados pelas medidas governamentais, o imigrante não pode interferir na vontade política da nação e não tem representatividade" (THOMÉ, 2018, p. 182). 
NUNES, M. F. R.; HEIDERIQUE, D. S

Não podendo exercer direitos políticos, essa parcela da população fica à mercê das políticas públicas e dependente de manifestações iniciadas por nacionais que visem melhorias em serviços e aquisição de direitos, como luta por mais vagas em creches para as crianças pequenas.

Tendo em vista que crianças refugiadas enfrentam problemas sociais parecidos com os que grande parte das crianças brasileiras vivenciam - falta de vagas em escolas, violência urbana, precarização da saúde, moradias em área de risco -, faz-se necessário acolher o questionamento sobre o que as diferencia. Para tanto, as contribuições de Thomé (2018), Chelotti e Richeter (2016), Tonin (2015) e Martuscelli (2014) devem ser consideradas.

A teoria da proteção integral, presente na Constituição Federal de 1988 e no Estatuto da Criança e do Adolescente (Lei n 8.069, de 13 de julho de 1990), afirma que as crianças devem ter prioridade nos recursos que as possibilite crescer e desenvolver-se de forma saudável e segura e que devem estar resguardadas de violências, explorações, descriminações, opressões ou de serem vítima de crueldades (BRASIL, 1988). Uma vez estando em território brasileiro, a criança em situação de refúgio está amparada por esses documentos. Porém, há questões específicas do refúgio que não são por eles consideradas.

Thomé (2018), ao relacionar as políticas externas e internas que regulamentam sobre a proteção integral, especificamente o Art. $3^{\circ}$ da Lei de Migração, sinaliza o vácuo existente entre a letra da lei as políticas públicas para estabelecer mecanismos para efetivar esse direito. Segundo a autora:

Existe uma lacuna nas normativas internacionais (Convenção de 1951) e nacionais (leis $9.474 / 97$ e $8.069 / 1990$ ) que não fazem menção as crianças e adolescentes refugiados, não se atentando para as peculiaridades deste grupo que, apresentando uma dupla vulnerabilidade, necessita de uma atenção redobrada, principalmente, as desacompanhadas e separadas (THOMÉ, 2018. p. 187).

Chelotti e Richeter (2016) corroboram essas ideias ao afirmarem que:

\footnotetext{
Uma criança refugiada não possui capacidade de falar por si, de decidir o rumo de sua vida, tampouco de defender-se de todo o processo degradante e desumano que o próprio refúgio traz, violando bem mais que direitos fundamentais, liberdade e dignidade, mas a sua infância, sua pureza e o seu direito de ser criança (CHELOTTI; RICHETER, 2016, p. 5).
}

Dessa forma, a vulnerabilidade de crianças refugiadas é agravada pela ausência de leis e políticas públicas específicas que lhes deem possibilidade de desenvolver-se de forma plena no país de acolhida após vivenciarem o refúgio e todos os desgastes físicos e mentais que estão associados a este. De acordo com Chelotti e Richeter (2016, p. 5), a criança refugiada sofre "um processo de desumanização do ser humano, ocasião que passa a justificar a submissão a condições subumanas, o impedimento do exercício de direitos básicos e da garantia do mínimo existencial". 
Rosemberg (2015, p. 221) define a criança como "profundamente marcada pelo meio social em que se desenvolve [...]. A criança, assim, não é uma abstração, mas um ser produtor e produto da história". Tecendo relações entre as contribuições dos autores que dissertam sobre a vulnerabilidade da criança refugiada (CHELOTTI; RICHETER, 2016; THOMÉ 2018; TONIN, 2015) e a contribuição de Rosemberg (2015), Kramer e Motta (2010) e Sarmento (2002) acerca da concepção da criança pela filosofia, pela sociologia ou pela psicologia, não se pode deixar de questionar sobre as condições e as vivências que a criança em situação de refúgio carrega, e como essas particularidades são trabalhadas e mediadas quando estas estão matriculadas em escolas brasileiras.

Tendo como base a análise da transcrição de entrevistas de cinco mulheres refugiadas, pode-se observar três eixos de análise que sobressaem nos relatos: a documentação, o idioma e o preconceito. Os depoimentos a seguir buscam visibilizar problemas e desafios enfrentados no cotidiano do refúgio que, segundo os relatos, permanecem mudos para a sociedade brasileira, pois não têm réplica e podem continuar na invisibilidade, tanto para as redes municipais de educação quanto para os professores e crianças que habitam (ou não) o universo do refúgio.

Sendo este um espaço novo para muitos que vivenciam o refúgio no Brasil, é relevante ter em mente que "a palavra é arena das contradições e sua compreensão é sempre ativa e fruto da coletividade. Há sempre uma réplica, uma contra palavra por parte daquele que ouve ou lê" (KRAMER; SOUZA, 1996, p. 17). Dessa forma, é possível que haja contradições tanto nas falas como nas suas interpretações, uma vez que estas refletem experiências tanto individuais quanto coletivas dos falantes e daqueles que ouvem dentro de seu contexto social e temporal.

“QUANDO VOCÊ É REFUGIADA E APRESENTA ESSES DOCUMENTOS [PROTOCOLO DE REFÚGIO] NINGUÉM ACEITA E PEDE PARA VOLTAR" - A DOCUMENTAÇÃO E A BUSCA POR RECONHECIMENTO

A documentação é um dos principais desafios para o acesso a direitos e serviços. Diversas instituições desconhecem o protocolo de refúgio e a legitimidade deste como um documento oficial de identificação. Neste ponto, podemos abrir margem ao questionamento de se a relutância de instâncias públicas e privadas em aceitar o protocolo como um documento de identidade está ligada a uma forma de isolamento social provocada pelo próprio sistema governamental.

A Lei de Refúgio determina no seu Art. $44^{\circ}$ que "O reconhecimento de certificados e diplomas, os requisitos para a obtenção da condição de residente e o ingresso em instituições acadêmicas de todos os níveis deverão ser facilitados, levandose em consideração a situação desfavorável vivenciada pelos refugiados" (BRASIL, 1997). Já o parágrafo primeiro do Art. $23^{\circ}$ da Lei de Diretrizes e Bases da Educação Nacional (LDBN) determina que "a escola poderá reclassificar os alunos, inclusive quando se tratar de transferências entre estabelecimentos situados no País e no exterior, tendo como base as normas curriculares gerais" (LDBN, 1996). Estes dois documentos legais são fundamentais para garantir o acesso à educação de toda criança em situação de refúgio. Ainda assim, mães refugiadas encontram barreiras para matricular seus filhos em escolas 
NUNES, M. F. R.; HEIDERIQUE, D. S

devido à ausência da documentação padrão e por falta de conhecimento dos gestores escolares.

Por meio do relato de uma das entrevistadas é possível perceber o impacto do não reconhecimento do protocolo de refúgio como um documento de identidade para o acesso à escola:

\begin{abstract}
A primeira dificuldade que a gente costuma encontrar para a escola é o protocolo. É um documento que ainda não é bem reconhecido no Brasil. É muito difícil aceitarem. Às vezes um refugiado não é imigrante, às vezes chega sem nenhum papel [documento] e não tem como se apresentar na escola (CAMÉLIA*, ENTREVISTA, 2018).
\end{abstract}

O protocolo de refúgio é o único documento de identificação que solicitantes de refúgio têm no Brasil. Ele deve ser aceito da mesma forma que outros documentos de identidade válidos em território nacional.

Quando você é refugiada e apresenta esses documentos [protocolo de refúgio] ninguém aceita e pede para voltar. Eu fui com uma pessoa brasileira e com o documento da Cáritas. Essa pessoa nos ajudou a ir à prefeitura. Chegamos lá, ela falou que eu era refugiada e que precisava de escola para as meninas e eles deram a vaga. Era distante, mas deram (MAGNÓLIA*, ENTREVISTA, 2018).

A falta de conhecimento das instituições de ensino sobre a obrigatoriedade de aceitar esse documento de identidade como oficial apareceu diversas vezes nos relatos. Para contornar a escassez de documentos exigidos pela rede pública, refugiadas já saem do PARES com uma carta de encaminhamento contendo os respaldos legais para a efetivação da matrícula, com a assinatura de uma assistente social e um advogado da instituição. Ainda assim, algumas relatam o encaminhamento errado por parte das secretarias de educação que resulta em dias de busca por pessoas e espaços onde a matrícula possa ser efetivada.

As falas das entrevistadas e a necessidade de um representante brasileiro, seja presencialmente ou através de um documento, evocam as considerações de Adriana Capuano de Oliveira (2017) acerca das identidades enquanto uma construção social em um Estado diferente do de origem:

Desde tempos imemoriáveis, sabemos que pertencemos a um grupo e que aqueles que não pertencem a esse grupo são, em consequência, diferentes de nós. Esse sentimento persiste ao longo da história humana evocando constantemente a percepção daqueles que são meus iguais, aos quais se elaboram relações de reciprocidade e confiança, vínculos solidários, e os diferentes, aos quais cabe a desconfiança, o estranhamento e, por vezes, a repulsa (OLIVEIRA, 2017, p. 95).

A efetivação da matrícula nas condições apresentadas por Magnólia* legitima o sentimento de estranhamento descrito por Oliveira (2017), ao passo que a desconfiança diante de um estranho, aquele com o qual a nacionalidade e a cultura não são 
compartilhadas, é momentaneamente superada quando a busca por vaga é apoiada por aquele com o qual são estabelecidas relações de igualdade social e cultural. De acordo da Silva (2000, p. 82), "a identidade está sempre ligada a uma forte separação entre 'nós' e 'eles'. Essa demarcação de fronteiras, essa separação e distinção, supõem e, ao mesmo tempo, afirmam e reafirmam as relações de poder".

De acordo com a entrevista da coordenadora do serviço social do PARES, houve avanços na cobrança de documentos para matrícula:

\begin{abstract}
Tivemos momentos em que o fato de não ter certidão de nascimento era um empecilho para acesso à escola. Conseguimos, conversando com as equipes e com gestores, que eles entendessem que essa não poderia ser uma exigência já que eles são refugiados ou solicitantes de refúgio e os documentos que eles têm que exigir são os que eles conseguem aqui no Brasil via Polícia Federal e Receita Federal (DEBORA ALVES, ENTREVISTA, 2018).
\end{abstract}

Traçando um paralelo entre a Lei de Refúgio, a Lei de Diretrizes e Bases da Educação Nacional (LDBN) e os relatos apresentados, é possível perceber que, apesar das determinações dos documentos, ainda existem barreiras que impedem mulheres refugiadas de matricular seus filhos de forma autônoma, sem a necessidade de cartas de recomendações fornecidas pela ONG, apoio de assistentes sociais ou de voluntários brasileiros.

Ao longo da pesquisa foi relatado também a cobrança de documentos escolares do país de origem ou de certidão de nascimento brasileira ao longo do ano letivo, uma vez que este não foi entregue no ato da matrícula. Essa cobrança pode ser considerada ilegal e constrangedora. O tempo transcorrido entre o ato da matrícula e o caminhar das aulas não possibilitará a aquisição desses documentos. O contato com o país de origem para tanto pode ser considerado um risco desnecessário e é amplamente desencorajado pelo governo brasileiro, podendo impactar negativamente o processo de refúgio.

Por ser um documento de identificação intermediário, ou seja, um documento temporário que habita entre o passaporte, seja legal ou falso, e o Registro Nacional de Estrangeiro (RNE), o protocolo de refúgio é o caminho que todo solicitante trilha em complexa busca por identidade, onde é necessário o enfrentamento com o próprio Estado, bem como com seus representantes (LACERDA; GAMA, 2016).

\title{
“O MEU PROBLEMA É A LÍNGUA, O PORTUGUÊS, QUE TENHO DIFICULDADE DE ESCREVER, MAS EU ENTENDO OUTRAS COISAS" - A LÍNGUA E O DESAFIO DA ALFABETIZAÇÃO
}

Petrus, Santos e de Aragão (2016) investigaram como as escolas lidam com as diferenças promovidas pela integração de crianças estrangeiras e refugiadas em sala de aula. A pesquisa feita pelas autoras foi centrada nas escolas localizadas no bairro de Brás de Pina, no município de Duque de Caxias, com presença de alunos refugiados.

Para tanto, entrevistaram moradores do bairro para traçar o contexto histórico da presença de refugiados africanos na região, além de gestores e professores das escolas da localidade que tinham matriculadas em seu corpo discente crianças 
NUNES, M. F. R.; HEIDERIQUE, D. S

refugiadas. Neste cenário, o trabalho das autoras é importante por apresentar a perspectiva das escolas que acolhem crianças refugiadas, sendo o contraponto das entrevistas coletadas. Dentre os relatos apresentados pelas autoras, há a fala de uma professora que expõe os desafios da enturmação e do rendimento escolar dos alunos:

Eles vêm com um encaminhamento da CRE (Coordenadoria Regional de Educação). Para a gente nivelar. Só que eles não falam nem escrevem português. Então, como vamos fazer o nivelamento? Aí mandamos de volta para a CRE para nos ajudarem; para eles fazerem o nivelamento. Pela idade deles deveriam estar no $3^{\circ}$ ano. Mas a gente vê que nem precisa prova para nivelar. Porque se eles não sabem ler e escrever, a gente teria que colocar no primeiro ano. Ou em uma turma especial que tem um projeto específico para alunos atrasados; para os que não sabem ler nem escrever. Nós colocamos lá. E eles terminam o ano sem saber escrever nem ler direito. Na verdade, eles aprendem a linguagem é mesmo no convívio lá na comunidade (PETRUS, SANTOS; DE ARAGÃO, 2016, p. 45).

O relato acima é relevante uma vez que reflete a forma como a escola vê e lida com o ingresso de alunos em situação de refúgio. Se por um lado há a obrigatoriedade da matrícula e a integração destes no espaço escolar, há também os desafios próprios da escola e do corpo docente para lidar com aquele que não se encaixa em um padrão.

De acordo com as autoras, "não existe uma diretriz única da Secretaria Municipal que facilite ou oriente o trabalho das escolas e seus professores com estes alunos" (PETRUS; SANTOS; DE ARAGÃO, 2016, p. 44). Embora haja a indicação de que se deve criar estratégias específicas para os alunos refugiados, as autoras afirmam que nas escolas estudadas o acolhimento de tais alunos era diretamente relacionado às formações prévias do corpo docente e atividades extra ocupacionais relacionadas à migração e ao refúgio desenvolvidas por funcionários (PETRUS; SANTOS; DE ARAGÃO, 2016, p. 43).

Acerca das dificuldades de aprendizado da língua portuguesa para a integração, tanto na sociedade quanto na escola, a entrevistada Magnólia* relata sua entrada na rede de educação, na modalidade da Educação de Jovens e Adultos (EJA), para acompanhar e auxiliar as filhas na trajetória escolar:

Eu estudei no Congo [Rep. Dem. do Congo], mas aqui, o tempo todo em que estou aqui, fui à escola. Me ajudaram também a entrar na escola porque na igreja em que eu estava morando falaram que eu era analfabeta. Uma pessoa apareceu e disse que queria me ensinar, quando ele falou para eu escrever eu comecei a escrever. Ele então falou que eu tinha capacidade de aprender. Me levou na escola pública e me ajudou a fazer a matrícula e eu estudo lá desde então. Terminei o $8^{\circ}$ ano no ano passado e esse ano eu acabei o ensino fundamental. Eles me avaliaram e falaram que eu preciso ir para o ensino médio porque eu tenho capacidade, o meu problema é a língua, o português, que tenho dificuldade de escrever, mas eu entendo outras coisas (MAGNÓLIA*, ENTREVISTA, 2018). 
Não falar português no momento da sua chegada resultou no estigma de ser analfabeta. Porém, conforme relatado, "a língua é o único problema" que a entrevistada precisa superar para completar seus estudos e obter o diploma de ensino médio. Nesse sentido, é como se todo o conhecimento prévio à sua chegada no Brasil fosse descartado ao ponto de ser vista como analfabeta.

\begin{abstract}
As professoras entravam na sala e eu sempre ficava no meu canto porque não entendia o português que elas falavam, mas quando lançavam matéria eu entendia por que, por exemplo, na geografia eu conseguia definir alguma coisa daí me saia bem. Meu problema é só falar. As professoras falam que eu tenho gramática curta e recomendaram que eu procurasse um site para aprender mais (MAGNÓLIA*, ENTREVISTA, 2018).
\end{abstract}

Segundo Bakhtin (1988), não recebemos a língua materna como algo pronto e acabado, mas, ao nascer, penetramos na corrente da comunicação verbal. Para o autor, são evidentes e necessárias as relações lógicas na língua, mas elas são apenas uma parte pequena da trama das relações dialógicas, ou seja, do diálogo entre pessoas. Ainda segundo o filósofo, não há neutralidade nos discursos; eles apresentam sempre uma dimensão avaliativa e expressam um posicionamento social: "Na realidade não são palavras o que pronunciamos ou escutamos, mas verdades ou mentiras, coisas boas ou más, importantes ou triviais, agradáveis ou desagradáveis, etc. A palavra está sempre carregada de um conteúdo ou de um sentido ideológico ou vivencial" (BAKHTIN, 1988, p. 95).

A entrevistada Zínia*, ao relatar o ingresso de sua filha mais velha na escola, afirma: "Ela já estudava no Congo e lá ela estava na 3a série, mas me falaram que não podiam colocar ela nesse ano no Brasil e aí foi difícil porque ela teve que voltar para o $1^{\circ}$ ano e começar de novo" (Zínia*, entrevista, 2018). A dificuldade apresentada pela filha de Zínia* é resultado não apenas do aprendizado do português em processo, mas pela não legitimação dos conhecimentos adquiridos no país de origem.

Em entrevista a uma professora da Escola Municipal F. J. Oliveira Viana, no bairro de Brás de Pina, Petrus, Santos e de Aragão (2016) obtiveram o seguinte depoimento:

Esses alunos [refugiados] não podem ser alfabetizados como uma criança brasileira. Porque eles vêm de um mundo diferente, com uma bagagem diferente, carregam uma cultura diferente. Mesmo eles morando hoje numa mesma comunidade, eles têm talvez, alguns deles, pelas histórias que nós conhecemos, certos traumas, certas características que muitas das nossas crianças não têm [...]. Os pais não sabem português. Os pais vão orientar na cultura e na língua que eles conhecem. A gente infelizmente não tem esse apoio. Nós temos que nos virar por aqui [...] para ajudar essas crianças, que geralmente sofrem e ficam defasadas na alfabetização da língua portuguesa (PETRUS; SANTOS; DE ARAGÃO, 2016, p. 49). 
NUNES, M. F. R.; HEIDERIQUE, D. S

O relato impactante apresentado pelas autoras serve de material para diversas interpretações e pode ser analisado por várias vertentes, porém, o que se mostra evidente é a ausência de preparo do corpo docente para acolher e direcionar ações de construção de conhecimento para alunos refugiados. Diversos fatores podem ser captados nas entrelinhas: ausência de uma estrutura pedagógica e curricular que apoie e oriente o trabalho do professor regente diante do desafio de alfabetização de uma criança refugiada; denúncia das condições de trabalho que promovem apenas o improviso, o "se virar", como dito pela professora na entrevista; carência de formações continuadas ou cursos específicos voltados ao trabalho com crianças em situação de refúgio e, por fim, a caracterização da criança refugiada como diferente e, por isso, inviabilizadora da alfabetização nos moldes tradicionais.

É possível conjecturar que crianças estrangeiras - e aqui não citamos exclusivamente as refugiadas - demandam mais atenção e recursos quando no ambiente escolar do país de acolhida, todavia, a hipótese de que estas não se alfabetizam da mesma forma que crianças brasileiras, conforme relatado pela professora, levanta reflexões acerca das práticas e métodos de alfabetização utilizados no espaço escolar.

Traçando um paralelo entre a fala da entrevistada Zínia* sobre sua filha, que precisou retornar ao $1^{\circ}$ ano, e o posicionamento da professora, é possível questionar o quanto de fato é necessário o retorno ao início do ciclo de alfabetização se, mesmo quando isso ocorre, há o despreparo e ausência de apoio do corpo docente para que ocorra a alfabetização em língua portuguesa. De fato, o início do ciclo estabelece mais possibilidades de atingir a alfabetização, porém, sem os instrumentos e o preparo necessário, pode se tornar apenas impedimento e desencorajamento para a permanência na escola, podendo culminar na evasão escolar.

“EU QUERIA QUE ELAS CONVERSASSEM COM AS AMIGAS DELAS. É UMA COISA IMPORTANTE PORQUE QUANDO VOCÊ ESTÁ EM UM LUGAR E NINGUÉM FALA CONTIGO... A PESSOA SE SENTE ISOLADA, NÉ?" - O PRECONCEITO

Ao longo das entrevistas, as mães refugiadas ressaltaram o isolamento social e o preconceito vivenciados pelas crianças. Em alguma medida, todas elas apontaram situações e falas que evidenciaram práticas discriminatórias direcionada às suas crianças no espaço escolar. Há relatos de racismo, xenofobia e até violência física. $O$ mais marcante é da entrevistada Kalanchoe* ${ }^{*}$ que teve sua filha empurrada da escada:

Estava na hora da saída e o colega que estava atrás dela na fila a empurrou do alto da escada e ela foi rolando até o final. Eu, em casa, eu não fiquei sabendo de nada. O diretor a pegou e a levou no hospital e de lá que me ligaram avisando que ela tinha sido empurrada por um colega (KALANCHOE*, ENTREVISTA, 2018).

Questionada sobre as providências tomadas pela escola em relação ao acidente, a entrevistada relatou a dificuldade na relação com o espaço educacional e como, por vezes, acontecimentos ocorridos dentro do espaço escolar, quando relatados por sua filha, são deslegitimados por parte da gestão: 


\begin{abstract}
Não sei por que às vezes quando acontece alguma coisa e você vai reclamar com eles [a direção] logo perguntam se a gente tem certeza. Aí você já sabe, né? Em casa, se minha filha me conta alguma coisa, eu tenho que perguntar se é verdade e ela me relata o que aconteceu. Quando você vai na escola eles logo perguntam: "você tem certeza, mãe? Porque você está acusando. E isso é grave" (KALANCHOE*, ENTREVISTA, 2018).
\end{abstract}

Por meio desse relato, podemos perceber os conflitos presentes não apenas na convivência das crianças com os alunos brasileiros, mas também na relação das responsáveis com a gestão escolar. Se por um lado há o desejo de amenizar as dificuldades enfrentadas pela sua filha, há também as questões próprias da escola em jogo que não podem ser ignoradas.

No estudo de Petrus, Santos e de Aragão (2016) há o relato de uma professora, alocada na Escola Municipal São Paulo, localizada em Brás de Pina, acerca dos conflitos enfrentados por alunos refugiados na escola:

Às vezes se envolvem em conflitos com os colegas. Os colegas implicam. Eles não entendem isso. Eles não entendem que os colegas não implicam porque são congoleses, mas porque sabem que alguns vão se "estourar". Isso também é o que acontece com os brasileiros; coisas de adolescentes... Botam apelido, sabe como é adolescente! (PETRUS; SANTOS; DE ARAGÃO, 2016, p. 45).

Ao afirmar que alunos refugiados não entendem que são alvos de intimidação, não por serem de outra nacionalidade, mas por ser algo "comum" da adolescência, a professora fornece um indicativo de como a escola pode compreender e direcionar suas ações contra situações de abuso e constrangimento.

Antunes e Soares Zuin (2008) realizaram uma ampla pesquisa acerca do bullying no espaço escolar e o caracterizaram como um compilado de comportamentos agressivos, físicos ou psicológicos que ocorrem entre pares no ambiente escolar sem motivação aparente, porém com maior incidência a grupos que divergem do que é considerado "normal". Assim, de acordo com o estudo dos autores, crianças e adolescentes que pertencem a grupos nômades - ciganos, artistas de circo, estrangeiros e outros - e alunos fora de um padrão físico normativo e não-heterossexuais são, estatisticamente, mais propensos a serem vítimas do bullying na escola. Nas palavras dos autores, "o bullying se aproxima do conceito de preconceito, principalmente quando se reflete sobre os fatores sociais que determinam os grupos-alvo" (ANTUNES; SOARES ZUIN, 2008, p. 24).

O fato de crianças refugiadas - que podem ser categorizadas como pertencentes de grupos nômades - serem alvos de violência física e psicológica nos espaços escolares corrobora a afirmação dos autores acerca destas serem, estatisticamente, mais propensas a ações de preconceito.

Compreendendo a complexidade do termo bullying nas práticas escolares brasileiras, acolhemos a afirmação de Marafon, Scheinvar e Nascimento (2014): 
NUNES, M. F. R.; HEIDERIQUE, D. S

As brincadeiras de gosto duvidoso sempre existiram entre as crianças e, portanto, sempre tiveram presença na escola brasileira, sendo resolvidas com escaramuças entre dois, às vezes mais, chegando mesmo às vias de fato de socos e pontapés, mas nunca atingindo o lugar da classificação, da denominação, do enquadramento, do controle dos corpos que a categoria bullying estabelece e define (MARAFON; SCHEINVAR; NASCIMENTO 2014, p. 94).

É relevante considerar que crianças refugiadas, devido aos possíveis traumas e desafios da adaptação compulsória no Brasil, ao serem alvo dessas "brincadeiras" comuns no espaço escolar, conforme relatado pelas autoras, podem não compreender e aceitar falas e posicionamentos discriminatórios da mesma forma que crianças brasileiras.

De acordo com Mireille Muluila, Agente de Integração local da Cáritas, também refugiada da República Democrática do Congo, as crianças em situação de refúgio, quando são alvos de falas e posicionamentos intimidadores por parte das outras crianças, tendem a evitar o espaço educacional.

\begin{abstract}
Algumas crianças já comentaram comigo que sofreram descriminação, ouviram xingamento e outras coisas ruins. Uma falou: "Ah Mama Mireille, eu não vou na minha escola porque os meus colegas me xingaram de feia e de macaca". As mães vão brigar na escola, falam lá porque ninguém pode admitir isso, que ninguém pode aceitar e que isso perturba muito a criança. $\mathrm{O}$ que a gente pode fazer é conversar com essa criança que sofreu esses xingamentos, essa descriminação, e dizer que não é verdade, que ela é bonita e linda (MIREILLE MULUILA, ENTREVISTA, 2018).
\end{abstract}

Nesta senda, há ainda o relato de Camélia*, que descreve o racismo praticado por meninas negras contra suas filhas:

Elas [as filhas] são muito diferentes! Muito diferentes mesmo! Mesmo não sendo negras assim como as negras daqui. São chamadas de cabelo duro, macaca do cabelo duro, entendeu? E as crianças estão sabendo disso aqui (CAMÉLIA*, ENTREVISTA, 2018).

Crianças negras brasileiras também sofrem e são alvos de falas pejorativas acerca da cor de sua pele ou a curvatura de seus cachos no espaço escolar, como denunciados pelos movimentos educadores concebidos nas lutas por emancipação dos negros (GOMES, 2017), porém, há de se considerar a fala da entrevistada que afirma que crianças refugiadas passam a conhecer o racismo em terras brasileiras quando antes só havia a descriminação por grupos étnicos em seu país de origem. Devido a isso, as falas preconceituosas das quais são alvos podem se tornar ainda mais problemáticas.

Ao longo das entrevistas, coletamos relatos acerca das ações tomadas pelas escolas para gerir situações de racismo e preconceito vivenciadas pelas crianças em situação de refúgio. A entrevistada Camélia* relata a omissão da escola: 
Quando chegam em casa as crianças choram, ficam triste e falam: "Mamãe, na escola estão falando que eu sou negra, macaca e que meu cabelo tá sujo. Minha amiga tem cabelo liso; cabelo bonito. $\mathrm{E}$ eu sou negra e quero ficar em casa". Eu quis falar com a diretora, ela não quis me receber. Aí fui pedir a transferência para a minha filha e ela não quis me dar a transferência. O professor pode se manifestar, só que o professor não liga, mesmo que tenha alunos xingando o outro, o professor ignora. Se o professor ignora isso significa que ele também tem parte. Fica do lado das crianças que estão ofendendo as outras (CAMÉLIA*, ENTREVISTA, 2018).

Por outro lado, as entrevistas das Magnólia* e Zínia* afirmam que a escola busca soluções para coibir e desencorajar falas preconceituosas no espaço escolar:

Elas [as outras crianças] ofendiam minha filha falando que o Brasil não é o país dela. Essas meninas são faveladas. Elas tratavam mal minha filha. Eu fui lá, conversei com o diretor e com a professora e aí melhorou. Agora minha filha fala bem da escola (ZÍNIA*, ENTREVISTA, 2018).

Um dia quando fui buscar ela [a filha mais velha] na escola, ela veio reclamando e chorando porque uma menina tinha dito que ela era feia. Quando ela me contou, eu aproveitei que vi o pai da menina e eu falei para ela falar com ele e eu disse para a minha filha: "você é uma menina linda". O pai daquela menina quando escutou, reclamou com a filha dizendo que ele não a ensinava assim e disse que eles iriam conversar em casa. Elas encontram preconceito, mas no cuidado das professoras ela não sentem não. (...) A escola é legal, elas estão bem e sem problema. Eu não tenho nada para me queixar (MAGNÓLIA*, ENTREVISTA, 2018).

O descontentamento das mães refugiadas com a escola também é perceptível no trabalho de Petrus, Santos e de Aragão (2016, p. 46) quando, ao tratarem sobre o relacionamento interpessoal no espaço educacional, colocam em questão a postura desta na gestão de conflitos. Porém, se por um lado há a crítica, há também o elogio por terem à disposição o acesso a uma escola pública gratuita (PETRUS; SANTOS; DE ARAGÃO, 2016, p. 41). Não há no Congo uma escola gratuita, todas exigem mensalidade ou algum tipo de pagamento para a frequência da criança. De acordo com a Agente de Integração, quando a família não tem recursos para manter a criança na escola, a frequência não é autorizada:

Você pode estudar onde quiser [no Congo], você pode colocar o seu filho onde quiser, mas não é de graça. Depende só das suas condições. As pessoas batalham, fazem de tudo para colocar a criança na escola, qualquer escola. As mães fazem de tudo. Se a mãe não tem dinheiro para pagar a criança não vai poder assistir aula. $A$ criança não vai estudar direitinho (MIREILLE MULUILA, ENTREVISTA, 2018). 
NUNES, M. F. R.; HEIDERIQUE, D. S

Assim, ao longo de quatro anos de convívio com mulheres refugiadas, foi comum ouvir que elas se sentiam gratas por ter oportunidade, mesmo sem recurso para tanto, de colocar seus filhos em escolas que oferecem merenda, uniforme e material escolar.

Relacionando a educação no Brasil com a educação na República Democrática do Congo, uma das entrevistadas relatou como a educação no seu país de origem apresenta relações próximas, quase tribais no ambiente escolar:

Tem um ensinamento no Congo de que você tem de obedecer a experiência. Obedece a sua irmã, obedece a sua prima, cada mulher que tem a idade da sua mãe é sua mãe. Cada mulher que tem a idade da sua irmã é sua irmã. Então, na escola a gente aprende tudo isso. Isso eu aprendi na escola. Eu represento a minha família. Cada criança representa a família. A professora perguntava qual é meu nome, eu respondia [nome da família ou sobrenome], esse nome representa a minha família. Se você faz alguma coisa errada, perguntam qual o seu nome de família, e isso é um insulto. Porque você mostra a sua casa. É um insulto para a família. Eu não posso brigar, eu não posso xingar, fazer coisa errada porque eu estou representando a minha família. Isso também é um insulto para mim, mas no Brasil não é assim! Você deixa as crianças soltas e elas batem nas outras crianças só porque elas são estrangeiras. Refugiadas (TULIPA*, ENTREVISTA, 2018).

Por meio do relato de Tulipa* é possível compreender, mesmo que de forma superficial, o funcionamento e as relações de poder que ocorrem no âmbito escolar do país de origem. Relações essas que fundamentam as críticas das mães refugiadas acerca da educação no Brasil.

A dupla vulnerabilidade da criança refugiada extrapola a arena do direito e da ausência de aparatos legais para consolidar a proteção integral; ela pode ser percebida também através da resistência de órgãos em aceitar a documentação disponibilizada, na dificuldade de comunicação pelo não domínio da língua portuguesa e na discriminação por ser estrangeira dentro do espaço escolar. São muitas barreiras a serem superadas por crianças refugiadas na busca de efetivar o direito à educação no Brasil.

\section{CONSIDERAÇÕES FINAIS}

Pode-se concluir pelos relatos e contribuições das mães refugiadas que os desafios que estas encontram para cumprir a obrigatoriedade da matrícula e acessar um espaço que também é de seus filhos por direito é penoso e por vezes constrangedor. Durante a pesquisa se constatou a ausência de leis e documentos específicos para tratar dos direitos e da proteção específica de crianças refugiadas que, ao nosso ver, necessitam de atenção especial devido à situação vulnerável na qual se encontram.

A carência de um aparato legal específico agrava os desafios da migração forçada, vivenciada tanto pelos responsáveis por matricular as crianças refugiadas quanto pelas próprias, colocando-as, dessa forma, em contexto de fragilidade agravada quando em contraste com as brasileiras no que tange o acesso à educação. 
As condições de entrada e de permanência de crianças refugiadas na escola, pelo olhar de suas mães, foram tratadas a partir de três eixos de análise que se destacaram nas entrevistas: a documentação, o idioma e o preconceito. Em relação à documentação, constatou-se que essa parcela da população fica à mercê das políticas públicas e dependente de manifestações iniciadas por nacionais. Outra questão levantada diz respeito à língua, pois não falar português no momento da chegada do refugiado ao Brasil resultou, de acordo com os relatos, no estigma do analfabetismo e, consequentemente, no retorno aos anos iniciais da Educação Básica. O preconceito e as formas com as quais este é compreendido pelas mães refugiadas - racismo, xenofobia e violência física - se apresentou como um desafio à integração das crianças na escola.

Diante das contribuições e dos relatos trazidos neste trabalho, faz-se necessário interrogar se o Brasil, enquanto nação considerada hospitaleira, está de fato consciente da crise humanitária mundial e disposta a acolher pessoas em situação de refúgio de forma igualitária, sem perpetuar preconceitos, racismos e discriminações, especialmente no espaço escolar com crianças vulneráveis. Mais do que isso, instiga-nos a pensar sobre o quanto estas questões estão presentes na forma como a sociedade brasileira lida com suas próprias crianças.

'THE SCHOOL ASKED FOR DOCUMENTATION AND I HAD TO EXPLAIN THERE'S ONLY THE PROTOCOL THAT THE FEDERAL POLICE GAVE US': REFUGEE CHILDREN AND EDUCATION

ABSTRACT: Considering the concept of double vulnerability of the refugee child, this article intends to shed light over the conditions in these refugee children are inserted into educational institutions through the eyes of their mothers. We seek to relate interviews with five refugee women from the Democratic Republic of Congo who had children enrolled in public schools in 2019 with legal apparatuses that regulate education in Brazil, specifically in matters of documentation for access to educational institutions. The analysis alows identification of three contitioning factors that shed light on the challenges of refugee children integration: the difficulties of access to public schooling due to the lack of recognition of the validity of refuge papers, language as a barrier for integration and the prejudice experienced inside the school environment.

KEYWORDS: Education. Infancy. Refuge. Public School.

"LA ESCUELA NOS PIDIÓ LA DOCUMENTACIÓN Y YO TUVE QUE EXPLANAR QUE SOLO HAY LO PROTOCOLO QUE NOS DIO LA POLICÍA FEDERAL": NIÑOS REFUGIADOS Y LA EDUCACIÓN 
NUNES, M. F. R.; HEIDERIQUE, D. S.

RESUMEN: Considerando el concepto de doble vulnerabilidad del niño refugiado, este artículo se propone a aclarar las condiciones en las cuales estes niños y niñas en situación de refugiados encajan en las escuelas a partir de la mirada de sus madres. Para tanto, el trabajo busca relacionar entrevistas realizadas con cinco mujeres refugiadas de la República Democrática del Congo que poseían hijos inscritos en la red pública de educación en el año de 2019, con el aparato legal que regula la educación en Brasil, específicamente en referencia a la documentación para acceder a la institución educativa. El análisis permitió reconocer tres condiciones que sacan a la luz los desafíos de la integración de los niños refugiados: las dificultades de acceder a la escuela pública debido al ni reconocimiento de la validad de la documentación de refugio en territorio brasileño, el idioma como obstáculo para la integración y el prejuicio dentro del entorno escolar.

PALABRAS CLAVE: Educación. Infancia. Refugio. Escuela Pública.

NotA

* Nomes fictícios.

\section{REFERÊNCIAS BIBLIOGRÁFICAS}

AMORIM, M. O Pesquisador e seu outro: Bakhtin nas ciências humanas. São Paulo: Musa, 2001.

ANTUNES, D. C.; SOARES ZUIN, A. Á. Do bullying ao preconceito: os desafios da barbárie à educação. Psicologia \& Sociedade, Minas Gerais, v. 20, n. 1, janeiro-abril, p. 33-41 2008.

BAKHTIN, M. (VOLOSHINOV, V. N.). Marxismo e filosofia da linguagem. Problemas fundamentais do método sociológico na ciência da linguagem. Trad. Michel Lahud e Yara Frateschi Vieira. São Paulo: Hucitec, 1988.

BRASIL. Constituição Federal de 1988. Brasília: Senado Federal, 1988.

BRASIL. Lei n 13.445, de 24 de maio de 2017. Institui a Lei de Migração. Diário Oficial da União, 2017.

BRASIL. Lei no 8.069, de 13 de julho de 1990. Dispõe sobre o Estatuto da Criança e do Adolescente e dá outras providências. Diário Oficial da União, 1990.

BRASIL. Lei no 9.394, de 20 de dezembro de 1996. Estabelece as Diretrizes e Bases da Educação Nacional. Diário Oficial da União, v. 134, n. 248, 1996.

Inter-Ação, Goiânia, v.46, n.2, p. 662-678, maio/ago. 2021. Disponível em: <http://dx.doi.org/10.5216/ia.v46i2.67910>. 
BRASIL. Lei no 9.474, de 22 de julho de 1997. Define mecanismos para a implementação do Estatuto dos Refugiados de 1951, e determina outras providências. Diário Oficial da União, 1997.

CHELOTTI, J. de D.; RICHTER, D. Sobre a vulnerabilidade e inclusão: as políticas de assistência aos refugiados no Brasil e a sua (in)efetividade no que tange as crianças e adolescentes oriundos desses fluxos migratórios. Seminário Internacional Demandas sociais e políticas na sociedade contemporânea, UNISC, Santa Cruz do Sul, RS, 2016.

DA SILVA, T. T. A produção social da identidade e da diferença. In: DA SILVA, T. T. (org.). Identidade e diferença: a perspectiva dos estudos culturais. Petrópolis, Rio de Janeiro: Vozes, 2000. p. 73-102.

GOMES, N. L. O movimento negro educador: saberes construídos nas lutas por emancipação. Petrópolis, RJ: Vozes, 2017.

INEP. Instituto Nacional de Estudos e Pesquisas Educacionais Anísio Teixeira. Plano Nacional de Educação PNE 2014-2024: Linha de Base. Brasília, DF: Inep, 2006.

KRAMER, S.; MOTTA, F. M. N. Criança. In:OLIVEIRA, D. A.; DUARTE, A. M. C.; VIEIRA, L. M. F. DICIONÁRIO: trabalho, profissão e condição docente. Belo Horizonte: UFMG/Faculdade de Educação, 2010.

KRAMER, S.; SOUZA, S. J. Uma experiência humana, história de vida e pesquisa: um estudo da narrativa, leitura e escrita de professores. In: KRAMER, S.; SOUZA, S. J. (orgs.). História de professores: leitura, escrita e pesquisa em educação. São Paulo: Editora Ática, 1996. p. 13-42.

LACERDA, A. L.; P. S. GAMA, C. F. O solicitante de refúgio e a soberania moderna: a identidade na diferença. Lua Nova, São Paulo, v. 97, n. 97, janeiro-abril, 2016, p. 53-82. https://doi.org/10.1590/0102-6445053-080/97.

MARAFON, G.; SCHEINVAR, E.; NASCIMENTO, M. L. Conflitos enquadrados como bullying: categoria que aumenta tensões e impossibilita análises. Psic. Clin., Rio de Janeiro, v. 26, n. 2, p. 87-104, 2014.

MARTUSCELLI, P. N. A Proteção Brasileira para crianças refugiadas e suas consequências REMHU: Revista Interdisciplinar da Mobilidade Humana, Brasília, ano XXI, v. 22, n. 42, p. 281-285, jan./jun. 2014.

OLIVEIRA, A. C. Uma questão de identidade! Migrações e pertencimento na dinâmica do mundo globalizado. Revista USP, São Paulo, 2017, n. 114, p. 91-108. https://doi.org/10.11606/issn.2316-9036.v0i114p91-108. 
NUNES, M. F. R.; HEIDERIQUE, D. S

PETRUS, R.; SANTOS, M. S.; DE ARAGÃO, L. X. Filhos de refugiados congoleses no Rio de Janeiro: socialização e escolarização nas escolas da rede pública de ensino. In: BAHIA, Joana; SANTOS, Miriam (org.). Um olhar sobre as diferenças: a interface entre projetos educativos emigratórios. São Leopoldo: Oikos, 2016. p. 35-55.

ROSEMBERG, F. Políticas públicas e qualidade da educação infantil. In: ARTES, A.; UNBEHAUM (orgs.). Escritos de Fúlvia Rosemberg. São Paulo, Cortez Editora, 2015. p. 216-235.

SARMENTO, M. J. Imaginário e culturas da infância. Texto produzido no âmbito das atividades do Projeto "As marcas dos tempos: a interculturalidade nas culturas da infância". Projeto Pocti/CED/2002. Disponível em http://www.titosena.faed.udesc.br/Arquivos/Artigos_infancia/Cultura\%20na\%20Infancia .pdf. Acesso em: jan. 2020.

THOMÉ, R. G. A integração local de crianças e adolescentes refugiados desacompanhados e separados no Brasil: reflexões para o debate. PUC-RJ, Rio de Janeiro, O social em questão - Ano XXI, n. 41, p. 177-198, maio/ago. 2018.

TONIN, M. M. A (des)proteção dos direitos humanos de crianças envolvidas em conflitos armados. In: EVINCI (Evento de Iniciação Científica), 4., 2015, Curitiba, Anais [...],v. 1, n. 4, Curitiba: UniBrasil, 2015. p. 243-254.

Maria Fernanda Rezende Nunes: Professora Titular-Livre em Educação Infantil do Departamento de Didática da Universidade Federal do Estado do Rio de Janeiro. Possui sraduação em Psicologia pela Pontifícia Universidade Católica do Rio de Janeiro (1981), mestrado em Educação pela Universidade do Estado do Rio de Janeiro (1995) e doutorado em Educação pela Universidade Federal do Rio de Janeiro (2005). É professora do Programa de Pós-Graduação em Educação da UNIRIO. Coordena o grupo de pesquisa Educação Infantil e políticas públicas (EIPP).

Orcid: https://orcid.org/0000-0003-3696-9369

E-mail: nunes.mariafernandarezende@smail.com

Domenique Sendra Heiderique: Mestra em Educação pela Universidade Federal do Estado do Rio de Janeiro (UNIRIO). Possui graduação em Pedagogia pela Universidade do Estado do Rio de Janeiro (2015). Atualmente é professora nos anos iniciais da Prefeitura da Cidade do Rio de Janeiro. Tem experiência na área de Educação, com ênfase em Refúgio e Migração.

Orcid: https://orcid.org/0000-0001-9454-9624

E-mail: nick.sendra@gmail.com

Este periódico utiliza a licença Creative Commons Attribution 3.0, para periódicos de acesso aberto (Open Archives Initiative - OAI). 